\title{
Metagenomic and Culturomic Approaches for Blueberry Biofertilizer Design ${ }^{\dagger}$
}

\author{
José David Flores Félix ${ }^{1, *(\mathbb{D})}$, Fernando Sanchez-Juanes ${ }^{2}$, Luis R. Silva ${ }^{1}$ and Gilberto Alves ${ }^{1}$ (D) \\ 1 CICS-UBI-Health Sciences Research Centre, University of Beira Interior, 6201-506 Covilhã, Portugal; \\ luisfarmacognosia@gmail.com (L.R.S.); gilberto@fcsaude.ubi.pt (G.A.) \\ 2 Instituto de Investigación Biomédica de Salamanca (IBSAL), Complejo Asistencial Universitario de \\ Salamanca, Universidad de Salamanca, 37007 Salamanca, Spain; fsjuanes@gmail.com \\ * Correspondence: jdflores@usal.es \\ + Presented at the 1st International Electronic Conference on Agronomy, 3-17 May 2021; Available online: \\ https://iecag2021.sciforum.net/.
}

check for

updates

Citation: Félix, J.D.F.;

Sanchez-Juanes, F.; Silva, L.R.; Alves, G. Metagenomic and Culturomic Approaches for Blueberry Biofertilizer Design. Biol. Life Sci. Forum 2021, 3, 49. https://doi.org/ 10.3390/IECAG2021-09668

Academic Editor: Youssef Rouphael

Published: 1 May 2021

Publisher's Note: MDPI stays neutral with regard to jurisdictional claims in published maps and institutional affiliations.

Copyright: (C) 2021 by the authors. Licensee MDPI, Basel, Switzerland. This article is an open access article distributed under the terms and conditions of the Creative Commons Attribution (CC BY) license (https:// creativecommons.org/licenses/by/ $4.0 /)$.

\begin{abstract}
Some decade ago, the blueberry (Vaccinium myrtillus) crop was introduced in Portugal and is widespread along the North and Center of Portugal. It has great relevance as an exportation product, taking advantage of the climatic conditions they allow to produce when the market does not have entrances from the producing countries of Northern Europe. However, this climate condition could create problems shortly since, if climate change models are correct, an increase in temperature and a reduction in precipitation will happen. In this work, we study the rhizospheric and endophytic population of wild blueberry plants in three locations of mainland Portugal intending to determine the core bacterial populations of these plants in Portugal to design new biofertilizers to improve the adaptation of this crop. The metagenomic approach revealed that the rhizospheric populations are influenced by temperature and climate, but the plant modulates the endophytic populations of Vaccinium. From this plant s total of 318 bacterial strains were isolated, and their infraspecific diversity has been analyzed using RAPD-M13, obtaining 66 different fingerprints, which were identified employing MALDI-TOF MS methodology and a comparison against the MALDI Biotyper 3.0 database. A $64 \%$ of the strains were identified at genus level and the remaining ones by $16 \mathrm{~S}$ rRNA sequencing. Bacillus, Serratia, Streptomyces, Paenibacillus, Pantoea, or Pseudomonas were some of the identified genera. Most strains were able to grow at $\mathrm{pH} 5.5$, in presence of $2 \% \mathrm{NaCl}$ and were psychoresistant. Plant growth promotion potential of these strains was analyzed revealing that most isolates were capable of solubilizing dicalcium phosphate, and only $17 \%$ of the isolates produced siderophores.
\end{abstract}

Supplementary Materials: The poster presentation is available online at https:/ / www.mdpi.com/ article/10.3390/IECAG2021-09668/s1.

Funding: This project has received funding from the European Union's Horizon 2020 research and innovation programme under the Marie Skłodowska-Curie grant agreement No. 101003373. 